\title{
Phase transformation kinetics and microstructure of NiTi shape memory alloy: effect of hydrostatic pressure
}

\author{
CENGIZ TATAR* and ZÜLKÜF YILDIRIM \\ Department of Physics, Faculty of Sciences, Firat University, 23169 Elazig, Turkey \\ *Author for correspondence (ctatar@ firat.edu.tr)
}

MS received 6 August 2015; accepted 2 November 2016; published online 28 July 2017

\begin{abstract}
The effect of hydrostatic pressure on the behaviour of reverse and forward transformation temperatures and physical properties of NiTi shape memory alloy has been investigated. The transformation temperatures and physical properties of the alloy change with applied pressure. It has been clearly seen from differential scanning calorimetry that with the increase of applied pressure, while $A_{\mathrm{s}}, A_{\mathrm{f}}$ and $M_{\mathrm{f}}$ transformation temperatures decrease, $M_{\mathrm{s}}$ value increases. Moreover, it is obvious that with the increase of applied pressure, Gibbs free energy increases by $5.2883 \mathrm{~J}$, while elastic energy increases by $1.4687 \mathrm{~J}$. In addition, entropy of the alloys decreases by $0.2335 \mathrm{~J}\left(\mathrm{~g}{ }^{\circ} \mathrm{C}\right)^{-1}$ with applied pressure. Additionally, it is evident from the scanning electron microscopy images of the samples that there is an obvious difference in the grain sizes of the unpressured sample and the samples on which pressure is applied, the sizes being 10-100 and 30-150 $\mu$, respectively.
\end{abstract}

Keywords. Phase transformation; differential scanning calorimetry; enthalpy; thermodynamic properties; microstructure.

\section{Introduction}

NiTi shape memory alloys (SMAs) are attractive materials for engineering and medical applications because they show the one-way effect (thermal memory) and pseudoelasticity (mechanical memory) [1,2]. Moreover, they have good chemical resistance and cyclic stability [3]. Martensitic transformation is a first-order diffusionless structural phase transformation between a high-temperature austenite phase and a low-temperature martensite phase [4-6]. Thermoelastic martensitic transformations are diffusionless crystal structural changes that proceed with the shear motion of crystallographic planes at the transformation interface. Furthermore, thermoelastic martensitic transformation is both a mechanical process and a thermal transformation process. Owing to this unique combination, specific thermodynamic conditions have been established to express the effects of stress and temperature, as the external driving forces, on the transformation. The shape memory effect is also related to the martensitic transformation that is essential, and an alloy exhibiting thermoelastic martensitic transition is deformed or bent at a temperature below the martensite finish temperature, $M_{\mathrm{f}}$. The specimen remains in the deformed shape on unloading and recovers the undeformed original shape on being heated over the austenite start temperature, $A_{\mathrm{s}}$, and regains the deformed shape on being recooled below $M_{\mathrm{f}}$ [7]. This shape change reoccurs during the heating and cooling processes within the martensitic region and a usable force arises during the martensite $\leftrightarrow$ austenite transformation with thermal cycling due to the shape recoverable properties. SMAs based on NiTi show the largest shape memory effect. In order to establish new fields of application, the knowledge of machining these materials is essential [8]. The martensitic transformation has also been studied from a technological viewpoint, partly because fine martensite structures formed in quenched ferrous alloys and steels are effective for strengthening and are thus used as structural materials, and partly because the shape memory effect and the pseudoelastisity effect appear in relation to the thermoelastic martensitic transformation and these effects are useful for practical purposes as functional materials. Thus, the martensitic transformation has recently been actively studied. Furthermore, NiTi SMAs are promising materials for impact applications because of their high damping capacity related to the hysteresis of the stress-induced martensitic B2 $\leftrightarrow$ B19 (B2 cubic type $\leftrightarrow$ B19 orthorhombic type or B19' monoclinic type) transformation. Moreover, these materials appear promising for civil engineering applications due to the high damping capacity [9-13], coupling with good strength, ductility and very good corrosion resistance. The aim of this study is to investigate the effect of hydrostatic pressure on the thermodynamic properties and physical properties transformation in $\mathrm{NiTi}$ SMA.

\section{Experimental}

The NiTi alloy used in this study was supplied by the Memory-Metalle Gmbh, Germany. The nominal composition is $\mathrm{Ni}-44.74 \mathrm{Ti}$ (wt\%). Samples cut from this alloy were annealed in the $\beta$-phase field for $30 \mathrm{~min}$ at $850^{\circ} \mathrm{C}$ for beta 
sizing and later rapidly quenched in iced brine in order to form the $\beta$ martensites. After different pressures (70, 140, 210,280 , and $350 \mathrm{MPa}$ ) were applied on the samples at room temperature the pressure was removed. Later, differential scanning calorimetry (DSC) measurements of unpressured and pressured $44 \mathrm{mg}$ samples were performed to determine the transformation enthalpies and the forward-reverse transformation temperatures of martensite $\Leftrightarrow$ austenite phase. Perkin-Elmer Sapphire DSC was performed with $10^{\circ} \mathrm{C} \mathrm{min}-1$ heating and cooling rates in -20 to $140^{\circ} \mathrm{C}$ range. The phase transformation parameters, martensite start temperature $M_{\mathrm{s}}$, martensite finish temperature $M_{\mathrm{f}}$, austenite start temperature $A_{\mathrm{s}}$, austenite finish temperature $A_{\mathrm{f}}$, austenite peak temperature $A_{\mathrm{p}}$, martensite peak temperature $M_{\mathrm{p}}$ and absorbed energy values during cooling and heating were automatically determined from DSC curves using Perkin-Elmer Sapphire DSC software programming. Microstructures of the alloy were investigated by scanning electron microscopy (SEM) using a JSM-7001F.

\section{Results and discussion}

The results of DSC studies of the samples unpressured and pressured at $10^{\circ} \mathrm{C} \mathrm{min}{ }^{-1}$ heating and cooling rates are presented in figure 1 . The austenite and martensite transformation temperatures were determined from the DSC curves and are given in table 1. During heating and cooling, a one-stage transformation is observed, namely, from the martensite $\left(\mathrm{B} 19^{\prime}\right)$ to the parent phase (B2). The martensitic transformation is a diffusionless first-order phase transition in crystalline solids, in which atoms move cooperatively $[14,15]$. The change in the

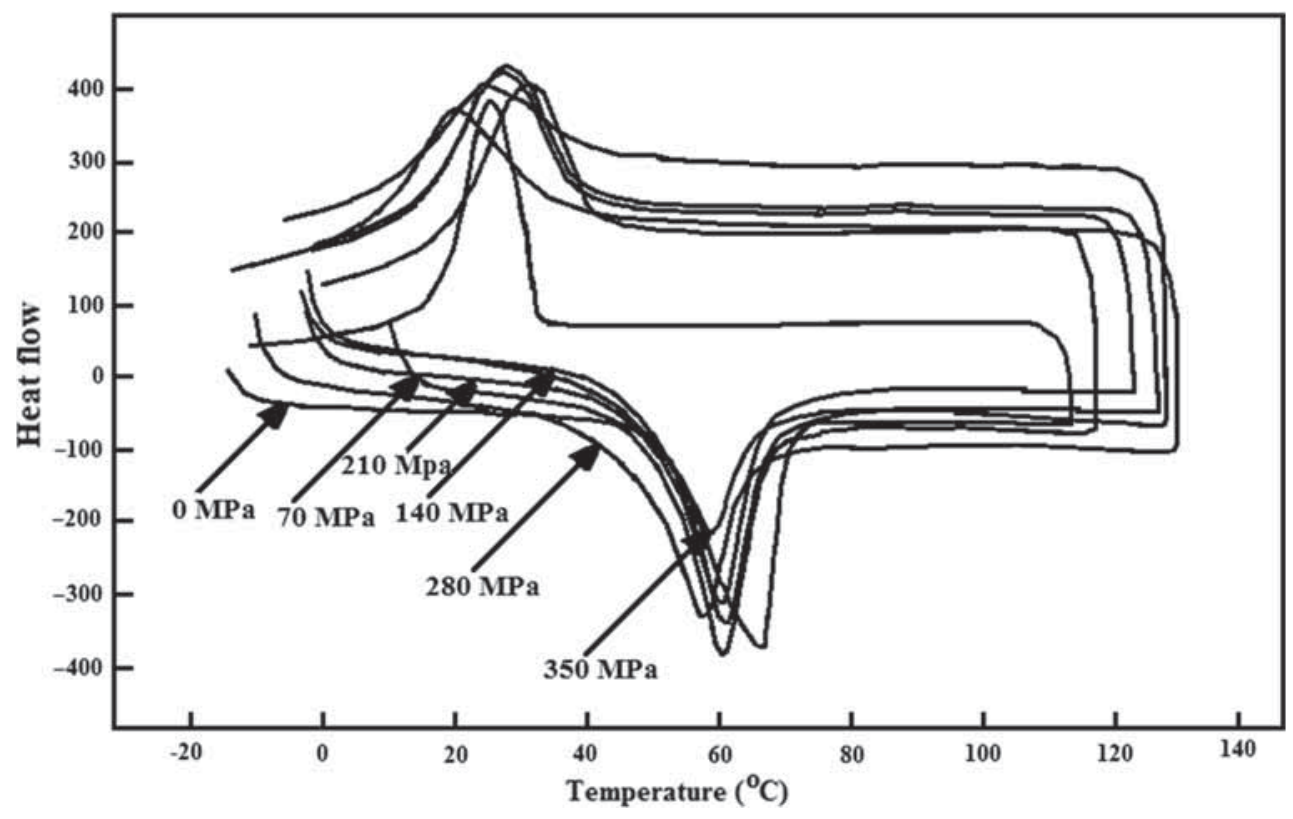

Figure 1. The DSC curves at the heating and cooling rates of $10^{\circ} \mathrm{C} \mathrm{min}^{-1}$ of samples unpressured and with applied pressure.

Table 1. The reverse and forward transformation temperatures and the absorbed energies obtained from the heating and cooling curves in figure 1.

\begin{tabular}{lrrrccc}
\hline Pressure (MPa) & $M_{\mathrm{S}}\left({ }^{\circ} \mathrm{C}\right)$ & $M_{\mathrm{f}}\left({ }^{\circ} \mathrm{C}\right)$ & $A_{\mathrm{S}}\left({ }^{\circ} \mathrm{C}\right)$ & $A_{\mathrm{f}}\left({ }^{\circ} \mathrm{C}\right)$ & $\Delta H_{\mathrm{H}}\left(\mathrm{J} \mathrm{g}^{-1}\right)$ & $\Delta H_{\mathrm{C}}\left(\mathrm{J} \mathrm{g}^{-1}\right)$ \\
\hline 0 & 32.7 & 17.4 & 51.5 & 69.9 & -19.1 & 22.3 \\
70 & 35.4 & 7.3 & 44.1 & 69.8 & -14.5 & 15.2 \\
140 & 34.3 & 8.4 & 45.6 & 67.5 & -13.6 & 15.6 \\
210 & 32.6 & 6.2 & 44.8 & 67.1 & -14 & 14.3 \\
280 & 35.9 & 5.7 & 45.7 & 66.9 & -13.5 & 13.5 \\
350 & 38.3 & 2.8 & 40.6 & 66.1 & -10.6 & 10.5 \\
\hline
\end{tabular}




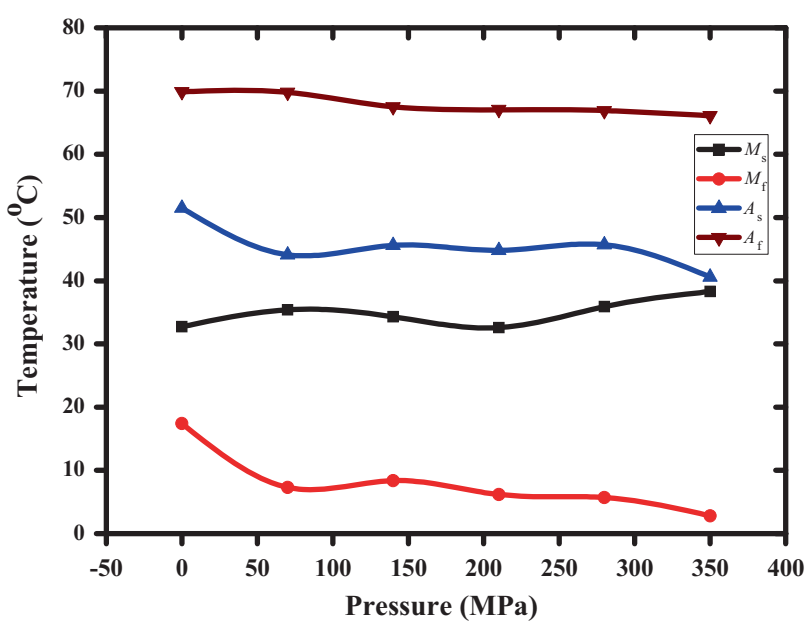

Figure 2. The change emerging in the transformation temperatures with applied pressure.

phase transformation temperatures with the applied pressure on the sample is given in table 1. It is obvious from the values given in table 1 that there have been changes in transformation temperatures due to the effect of the pressure applied on the sample. Figure 2 indicates the changes in the transformation temperatures of the sample resulting from the applied pressure. It is clearly seen that the $A_{\mathrm{s}}, A_{\mathrm{f}}$ and $M_{\mathrm{f}}$ transformation temperatures decrease, while $M_{\mathrm{S}}$ value increases with the increase of applied pressure. This indicates that the relative phase stability is altered by the applied pressure. Applied pressure leads to a decrease of $10.9^{\circ} \mathrm{C}$ in austenite start transformation temperature, while it causes an increase of $5.6^{\circ} \mathrm{C}$ in the martensite start transformation temperature. This suggests that the increase in pressure has the effect of conversion to more and more residual austenite and furthermore, it has the effect of causing a large shift in transformation temperatures. Additionally, it is clear from figure 1 that increase of applied pressure on the alloy causes reverse and forward transformation peak temperatures to decrease. The absorbed and released energy values of the alloy on which pressure was applied and the alloy that was unpressured, determined from DSC measurements, are shown in figure 3 . The pressure applied on the sample results in change in the absorbed and

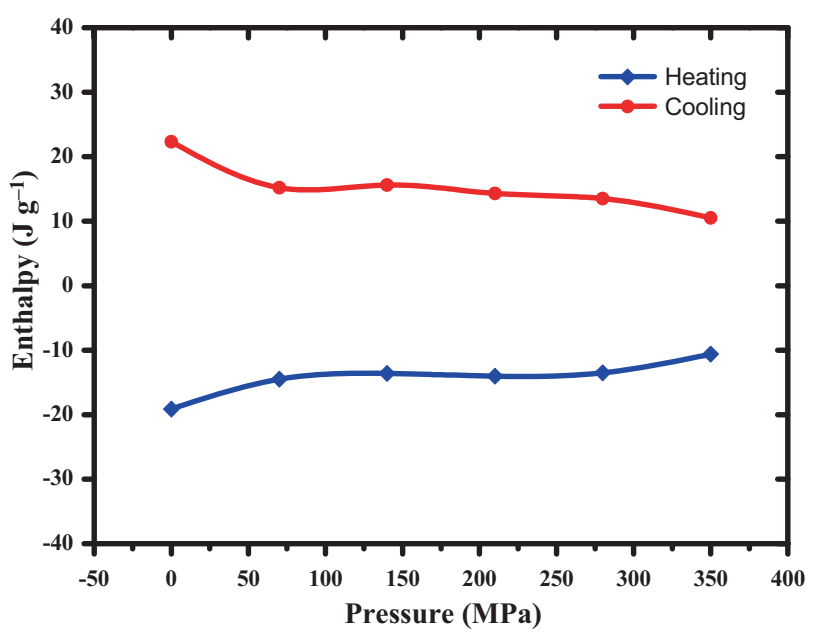

Figure 3. The enthalpy variation emerging in the alloy with pressure applied.

released energy values. This suggests that the pressure causes a decrease in the amount of the martensite phase. The decrease in the energy values results in a higher driving force for the reverse transformation. The decrease in the transformation temperatures of the alloys can be explained by the presence of cubic B2 structure in the parent phase in NiTi-based SMAs. Furthermore, according to the articles [3,16,17], thermoelastic martensitic transformations develop in three mechanisms: nucleation, growth and impingement of growing new phase particles. The applied pressure on the sample contributes positively to the three mechanisms in thermoelastic martensitic transformations mentioned here. The driving force for the nucleation of martensite at the temperature $M_{\mathrm{s}}$ is given by $[17,18]$

$$
\Delta G^{M \rightarrow P}=-\left(T_{\mathrm{o}}-M_{\mathrm{S}}\right) \Delta S^{M \rightarrow P}
$$

where $\Delta S^{M \rightarrow P}$ is the entropy change, and is calculated from the equation

$$
\Delta S^{M \rightarrow P}=\Delta H^{M \rightarrow P} / T_{\mathrm{o}}
$$

Table 2. Pressure effect on $T_{\mathrm{o}}\left({ }^{\circ} \mathrm{C}\right), \Delta H^{M \rightarrow P}\left(\mathrm{~J} \mathrm{~g}^{-1}\right), \Delta S^{M \rightarrow P}\left(\mathrm{~J}\left(\mathrm{~g}^{\circ} \mathrm{C}\right)^{-1}\right), \Delta G^{M \rightarrow P}(\mathrm{~J})$ and $\Delta E_{\mathrm{e}}$ (J).

\begin{tabular}{lccccc}
\hline Pressure (MPa) & $T_{\mathrm{o}}\left({ }^{\circ} \mathrm{C}\right)$ & $\Delta H^{M \rightarrow P}\left(\mathrm{~J} \mathrm{~g}^{-1}\right)$ & $\Delta S^{M \rightarrow P}\left(\mathrm{~J}\left(\mathrm{~g}^{\circ} \mathrm{C}\right)^{-1}\right)$ & $\Delta G^{M \rightarrow P}(\mathrm{~J})$ & $\Delta E_{\mathrm{e}}(\mathrm{J})$ \\
\hline 0 & 51.3 & 22.3 & 0.4346 & -8.0835 & 6.6493 \\
70 & 52.6 & 15.2 & 0.2889 & -4.9690 & 8.1180 \\
140 & 50.9 & 15.6 & 0.3064 & -5.0862 & 7.9357 \\
210 & 49.8 & 14.3 & 0.2871 & -4.9381 & 7.5794 \\
280 & 51.4 & 13.5 & 0.2626 & -4.0703 & 7.9305 \\
350 & 52.2 & 10.5 & 0.2011 & -2.7952 & 7.1390 \\
\hline
\end{tabular}




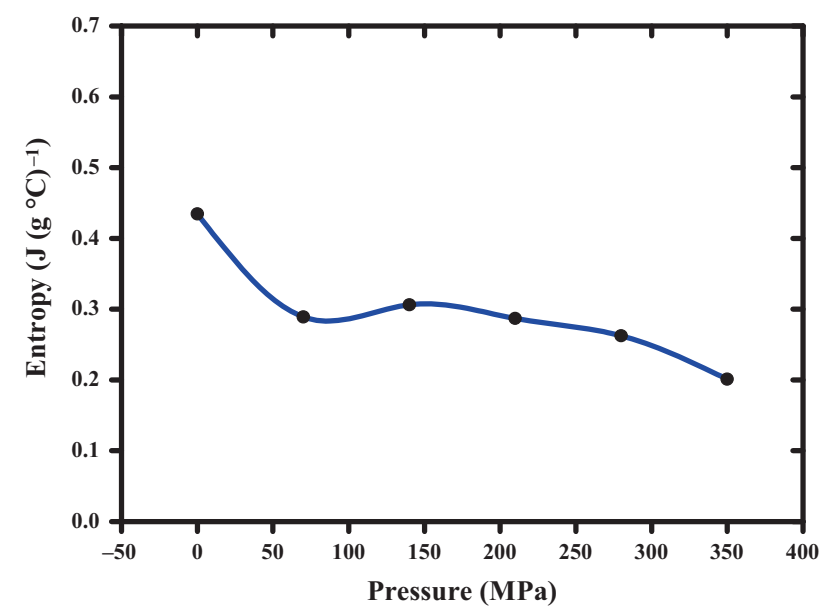

Figure 4. The shift of the entropy with pressure for the alloy.

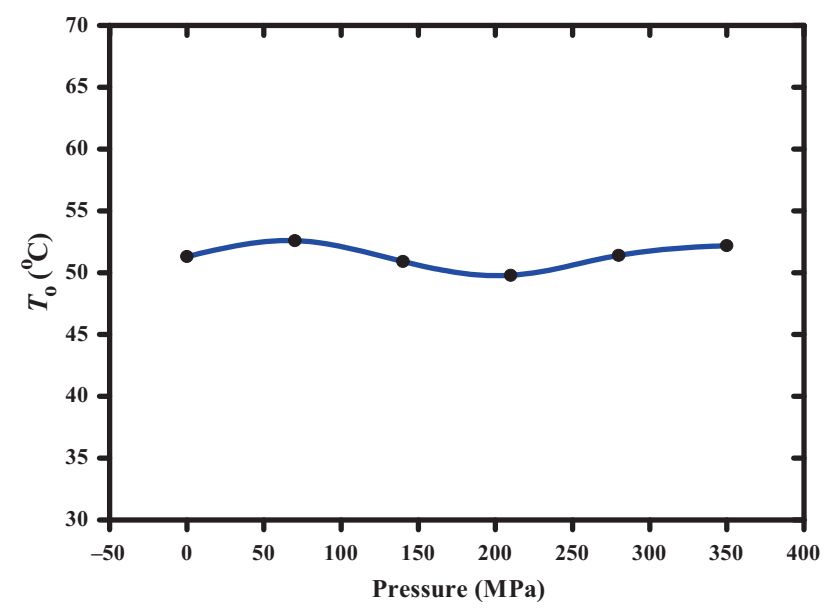

Figure 5. The variation of the thermodynamic equilibrium temperature of the alloy with pressure.

$T_{\mathrm{o}}$ is the equilibrium temperature, at which the Gibbs free energies of martensite and austenite are equal, and is calculated from the following equation as suggested by $[19,20]$ :

$$
T_{\mathrm{o}}=\left(\frac{A_{\mathrm{f}}+M_{\mathrm{s}}}{2}\right)
$$

$\Delta S^{M \rightarrow P}$ values of the samples calculated from equation (2) are given in table 2. Entropy change values of the alloy were determined and are shown in figure 4 . This shows that entropy of the alloys decreases with applied pressure. The decrease of entropy value with pressure increase can be explained as follows. A strain occurs in the inner structure of alloy due to the pressure applied. Since this strain leads to restriction in the motion of the atoms in alloy, they are in a more stable situation. As this stable situation of the atoms decreases system

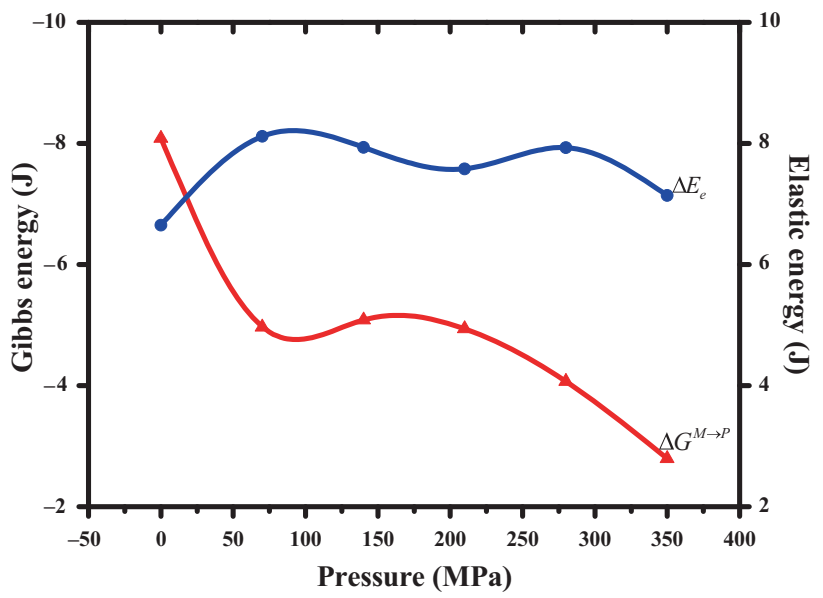

Figure 6. Plots of Gibbs free energy $\Delta G^{M \rightarrow P}$ and elastic energy $\Delta E_{\mathrm{e}} v s$. applied pressure of the alloy.

disorder, the forming phase becomes more stable. $T_{\mathrm{o}}$ values for the unpressured and pressured samples were determined from DSC curves and are given in table 2. Figure 5 shows the variation of $T_{\mathrm{O}}$ with applied pressure. As seen in figure 5, $T_{\mathrm{o}}$ values change with the applied pressure. This implies that the applied pressure increases the Gibbs free energies of the martensite and austenite phases and in turn, the transformation temperatures increase. Due to the nucleation, growth and the impingement mechanisms of thermoelastic martensitic transformations, a difference between $M_{\mathrm{s}}$ and $M_{\mathrm{f}}$ temperatures occurs on cooling the specimen, which is related to the elastic energy $\Delta E_{\mathrm{e}}$ stored in the self-accommodated martensitic variants. The elastic energy can be calculated using $[3,20]$ the relation

$$
\Delta E_{\mathrm{e}}=\left(M_{\mathrm{s}}-M_{\mathrm{f}}\right) \Delta S^{M \rightarrow P}
$$

The $\Delta E_{\mathrm{e}}$ values of the alloy calculated using equation (4) are given in table 2 . With the increase of the pressure applied to alloy, $\Delta E_{\mathrm{e}}$ values increase. These changes may be due to the stabilization of the martensite phase with respect to the parent phase. Moreover, the reason for the increase with the pressure can be explained as follows. While phase transformation is accompanied with less elastic energy in the unpressured sample, it is observed that strain in alloy increases with the pressure; the value of elastic energy is thought to increase in order to eliminate the strain and permit the transformation. As a matter of fact, elastic energy is a significant feature in the formation of thermoelastic phase transformation. To see clearly the changes of these quantities with pressure, the graphs for $\Delta G^{M \rightarrow P}$ and $\Delta E_{\mathrm{e}}$ are given in figure 6.

It is seen in figure 6 that with the increase of applied pressure, Gibbs free energy increases by $5.2883 \mathrm{~J}$, while elastic energy increases by 1.4687 J. Figure 7 shows the SEM images of the samples. As seen in figure 7, there are grains with various sizes in the SEM images. The surface morphology of the samples changes with applied pressure. 


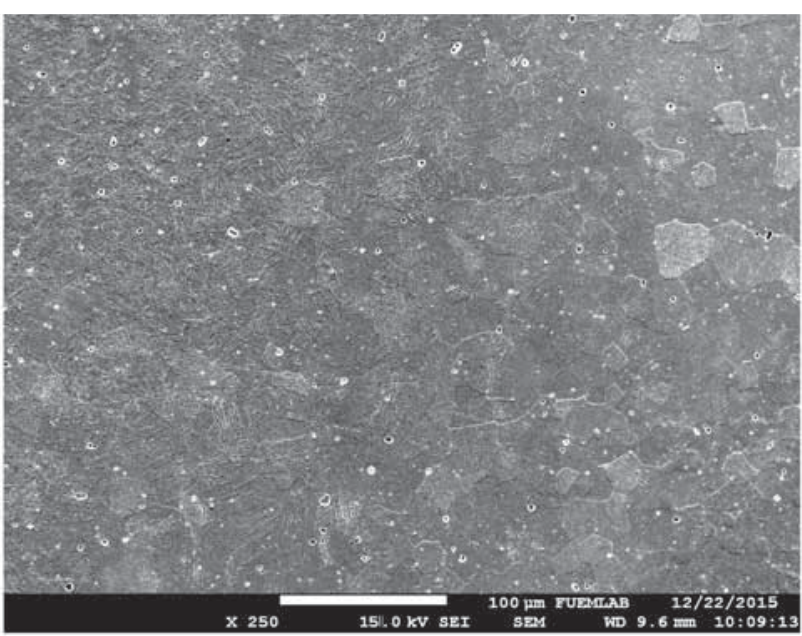

(a) Unpressured

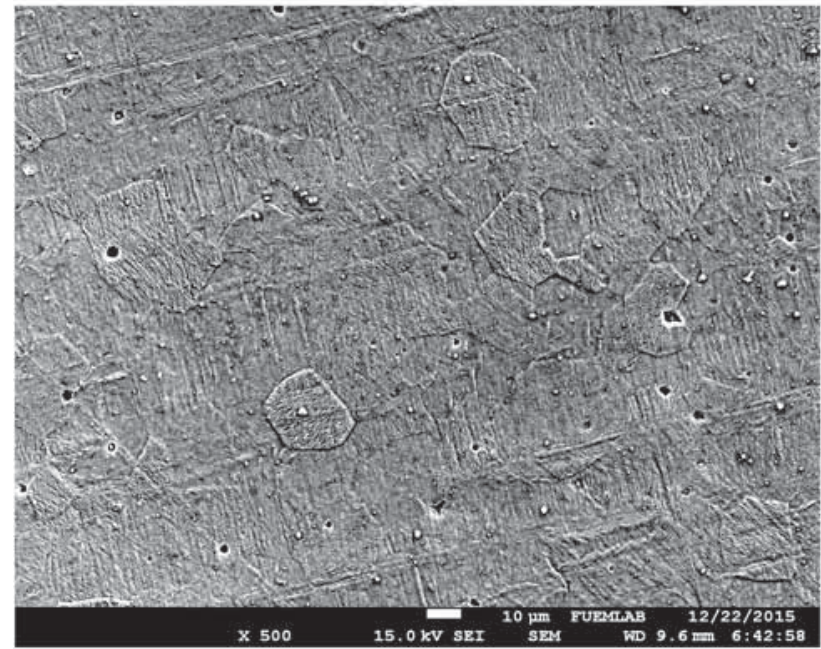

(b) $70 \mathrm{MPa}$

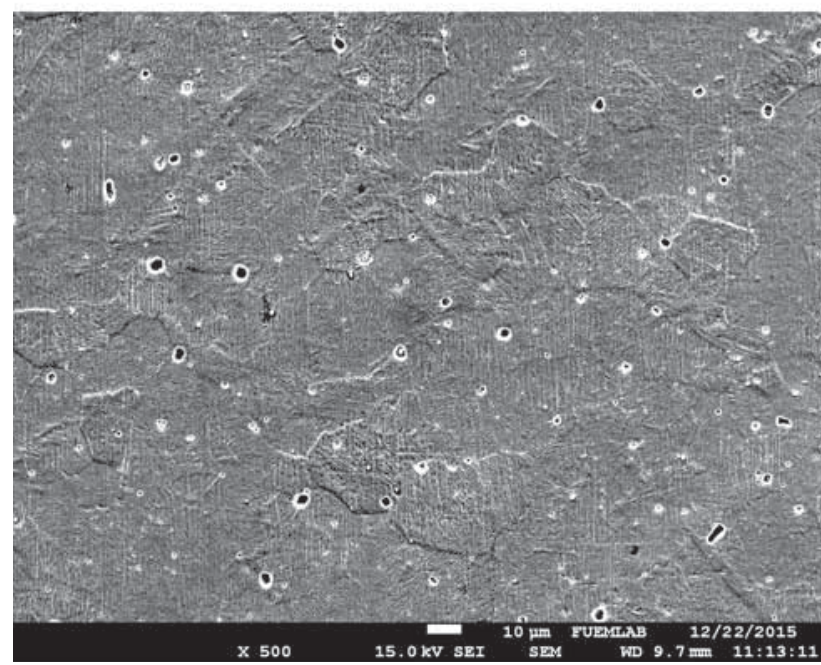

(c) $280 \mathrm{MPa}$

Figure 7. SEM images of samples unpressured and with applied pressure.

\section{Conclusions}

The effects of pressure on phase transformations temperatures of NiTi SMAs were investigated. The applied pressure causes some changes in austenite and martensite transformation temperatures. It is clearly seen that with the increase of applied pressure, Gibbs free energy increases by $5.2883 \mathrm{~J}$, while elastic energy increases by $1.4687 \mathrm{~J}$. The SEM images of the samples show that while grain sizes of the unpressured sample in figure $7 \mathrm{a}$ are between 10 and $100 \mu \mathrm{m}$, the grain sizes increase to $30-150 \mu \mathrm{m}$ in the samples on which pressure is applied as shown in figure $7 \mathrm{~b}$ and $\mathrm{c}$. These grain sizes were determined by the Image Analysis Method. It is thought that the applied pressure increase the grain sizes based on the results obtained. The obtained results indicate that the phase transformation temperatures and microstructure of the alloy change with applied pressure.

\section{Acknowledgements}

This work was supported by the Management Unit of Scientific Research projects of Firat University (FÜBAP) (Project Number: F.13.09).

\section{References}

[1] Saburi T, Otsuka K and Wayman CM (eds) 1998 Shape memory materials (Cambridge: Cambridge University Press)

[2] Otsuka K and Ren X 1999 Intermetallics 7511

[3] Humbeeck J 1999 Mater. Sci. Eng. A 134 273-275

[4] Delaey L et al 1974 J. Mater. Sci. 91521

[5] Tatar C and Zengin R 2005 Mater. Lett. 593304

[6] Tatar C 2006 Mater. Lett. 60120

[7] Dolce M and Cardone D 2001 Int. J. Mech. Sci. 432657

[8] Miyazaki S et al 1986 Metall. Trans. A 17115

[9] Liu Y and Van Humbeeck J 1997 Alloys J. Phys. IV 7519

[10] Schetky L M 1990 Duerig T W et al (eds) Engineering aspects of shape-memory alloys (London: Butterworth-Heinemann)

[11] Tatar C and Yakuphanoglu F 2005 Thermochim. Acta 430129

[12] Wanga Z et al 2011 Int. J. Smart Nano Mater. 2101

[13] Liu Y et al 1999 Scr. Mater. 4189

[14] Otsuka K, Wayman CM 1998 Shape memory materials (Cambridge University Press)

[15] Zengin R 2010 Thermochim. Acta 61503

[16] Porter D A and Easterling K E 1992 Phase transformations in metals and alloys 2nd edn (Padstow, UK: Chapman \& Hall and T. J. Press)

[17] Tatar C 2005 Thermochim. Acta 437121

[18] Daroczi L and Beke D L 2002 Philos. Mag. B 82105

[19] Kato H et al 2011 Acta Mater. 593955

[20] Zu X et al 2003 Mater. Lett. 572099 